\title{
Study on the Evaluation System of Higher Vocational Education Curriculum Based on Entire Process
}

\author{
Qingyue Zhang ${ }^{1, a}$, Juan Wen ${ }^{2, b},{ }^{*}$ \\ ${ }^{1}$ Chongqing Real Estate College, Chongqing, P.R.China \\ ${ }^{2}$ Chongqing Cheng Tou Road and Bridge Administration Co.Ltd, P.R.China \\ adinasilly@sina.com, b* Corresponding author wenjuan119@163.com
}

Keywords: Higher vocational education, Curriculum evaluation, Evaluation system, Practice.

\begin{abstract}
The reform and practice of the evaluation system of higher vocational education curriculum is the key point of higher vocational education reform. Taking the reform and practice of the theoretical core curriculum evaluation system of the higher vocational education as samples, this research establishes the identification model of " $2+1+1$ ", which is the combination of the daily performance, the midterm test, the final test and the comprehensive correction coefficient. In this research the DPS and other mathematical software are taken for data analysis. The research results show that when the ratio of the daily performance, the midterm test and the final test respectively accounting the final comprehensive evaluation results are $30 \%, 30 \%$ and $40 \%$, and the comprehensive correction coefficient is taken the root mean square of these three appraisal results, the identification model of " $2+1+1$ " is optimal for the evaluation of theoretical core curriculum assessment of the higher vocational education.
\end{abstract}

\section{Introduction}

Comprehensive evaluation system of higher vocational education curriculum is the key point of controlling the teaching quality, the evaluation of talents and the feedback of teaching information ${ }^{[1-2]}$. The reform of higher vocational education curriculum is an important part of the teaching reform of higher vocational education, and the evaluation of the curriculum in colleges and universities is an important factor to affect the quality of higher vocational education ${ }^{[3]}$.As the only quantitative standard for the students' individual learning effect, the traditional paper-pen test is an exam model that one test gives the final word. Its main purpose is screening, selection, rewards and punishments, but it is difficult to adapt to the value of the demands of modern higher education ideas, that of quality development, ability enhancement and cultivation of the consciousness of innovation ${ }^{[4-6]}$.

The primary task of the contemporary higher education practitioners is to explore a comprehensive evaluation system of higher vocational education curriculum, which has a clear appraisal purpose and broad contents of the evaluation scope based on the appraisal feedback function and has a variety of evaluation methods and reasonable performance evaluation ${ }^{[7]}$.

The teaching of theoretical curriculum in higher vocational education is an important teaching unit to impart theoretical knowledge. However, in terms of how to improve teaching quality, most colleges and universities are accustomed to pay more efforts on the construction of teaching staff and the teaching contents and methods while ignoring that the research and reform of the evaluation methods are also required to keep pace with the times and social development.. In fact, as an important part of personnel training, the evaluation method is very important to the teaching quality. Therefore it is imperative to explore the reform and practice of the evaluation system of theoretical curriculum and to carry out the evaluation method of multiple and dynamic. The curriculum comprehensive evaluation system should be based on the whole learning process of students ${ }^{[8]}$ in order to promote students' comprehensive abilities.

Based on years of teaching practice, authors have made a comprehensive analysis of the problems existing in the current evaluation methods. By taking some professional core courses of a Chongqing higher vocational college as the sample, authors propose concrete measures and methods for the 
reform of the evaluation methods, make a deep discussion on the key influencing factors on the reform and practice of the curriculum dynamic evaluation model based on the whole teaching process life cycle, and clarify the important practical value of the " $2+1+1 "$ curriculum dynamic evaluation system on guiding the theoretical curriculum teaching in higher vocational education, in order to accelerate the promotion of the teaching quality of higher vocational education.

\section{Construction of Curriculum evaluation system}

\subsection{Samples}

This curriculum evaluation system reform practice takes some professional theory core courses of a Chongqing higher vocational college as the sample. The identification model of " $2+1+1$ ", which is based on the daily performance, the midterm test and the final test supplemented by the comprehensive correction coefficient, is adopted to carry out the evaluation of teaching effectiveness and student's comprehensive ability.

\subsection{Overall framework of evaluation system}

The "2+1+1" curriculum evaluation system framework is set mainly for the theoretical curriculum teaching reform and practice of the higher vocational education. The theoretical core curriculum teaching in higher vocational colleges has been plagued by problems for a long time, for example students' enthusiasm for learning theoretical curriculum is not high, and the passing rate of the theoretical curriculum is relatively lower than that of practical training course. And that the old curriculum evaluation methods are not compatible with the talent training mode in the new period is another important factor at the same time ${ }^{[9]}$. The theoretical curriculum teaching is different from the theory and practice integration curriculum teaching mode. Therefore, it is necessary to explore a new construction for the curriculum evaluation system. The overall framework of this curriculum evaluation system is as shown in Table 1.

Table 1 Framework of curriculum evaluation system

\begin{tabular}{ccccc}
\hline & \multicolumn{3}{c}{ Factors of curriculum evaluation system } & \\
& $\mathrm{K}_{1}$ & $\mathrm{~K}_{2}$ & $\mathrm{~K}_{3}$ & correction coefficient \\
\hline \multirow{2}{*}{ score } & 100 & 100 & 100 & $\mathrm{~K}_{0}$ \\
\hline ratio & 0.3 & 0.3 & 0.4 & \\
\hline
\end{tabular}

The implementation program of the curriculum evaluation is designed as follows: The calculation of the daily performance score $\mathrm{K}_{1}$ is that the top score of $\mathrm{K}_{11}$ is 100 and that the score deduction factors include absenteeism, late coming and early going, while the score plus factors including classroom presentations, discussions, assignments, etc., and the concrete quantitative scale is mastered by the teachers. The midterm test score $\mathrm{K}_{2}$ is the midterm paper-pen test score. The final test score $\mathrm{K}_{3}$ is the final paper-pen test score. And the comprehensive correction coefficient $\mathrm{K}_{0}$, is calculated by this equation $=\sqrt{++} \quad$.Based on the " $2+1+1 "$ whole teaching process curriculum evaluation mode, the calculation equation for the comprehensive score of the curriculum evaluation $\mathrm{C}$ is $=++$. The comprehensive correction coefficient $\mathrm{K}_{0}$ is set to quadratic weighted students' daily performance scores, midterm scores and final scores, in order to as far as possible reduce the asymmetry between the quantitative score and the students' actual academic ability caused by the preference of the final test builders, and make the comprehensive score of the evaluation standard in the form of fraction more objective and impartial. From the point of view based on the author's teaching practice, the "2+1+1" mode of the curriculum comprehensive evaluation system can fully guarantee the order of teaching in schools, promote students` enthusiasm 
to participate in classroom interaction, and its teaching effect is remarkably superior to the traditional mode of "one test giving the word" .

\section{Discussion on the Practice of the identification model of " $2+1+1$ "}

\subsection{Case studies}

The data of the education reform practice is processed using the DPS mathematical statistics software, and the result is shown in Table 2.

Table 2 statistical analysis of each factor

\begin{tabular}{cccccc}
\hline & $\mathrm{K}_{0}$ & $\mathrm{~K}_{1}$ & $\mathrm{~K}_{2}$ & $\mathrm{~K}_{3}$ & $\mathrm{C}$ \\
\hline Median & 0.86 & 88.00 & 88.50 & 86.00 & 73.95 \\
\hline Mean deviation & 0.04 & 5.22 & 3.40 & 8.23 & 6.84 \\
\hline Range & 0.23 & 21.00 & 22.00 & 45.00 & 41.10 \\
\hline Standard deviation & 0.05 & 6.31 & 4.67 & 10.31 & 8.85 \\
\hline $95 \%$ confidence interval & $0.84 \sim 0.88$ & $84 \sim 89$ & $86 \sim 89$ & $80 \sim 87$ & $71 \sim 78$ \\
\hline
\end{tabular}

According to Table 2 it can be seen that the range of the comprehensive correction coefficient $\mathrm{K}_{0}$ is very remarkable, and its value is of 0.23 . This result coincides with the original intention of setting comprehensive correction coefficient $\mathrm{K}_{0}$ to realize the differentiation of the curriculum evaluation. The range of the comprehensive score $\mathrm{C}$ is much more remarkable, and its value is of 41.10 . This coincides with the results that the range of comprehensive correction coefficient $\mathrm{K}_{0}$ is remarkable while the mean deviation of these five factors are controlled in the range of $10 \%$, which indicate that the statistical factors of the experimental samples are of high reliability.

3.1.1 $K_{1}$-C deviation analysis

The relationship of the deviation between the daily performance score $\mathrm{K}_{1}$ and the comprehensive score $\mathrm{C}$ is shown in Fig1.

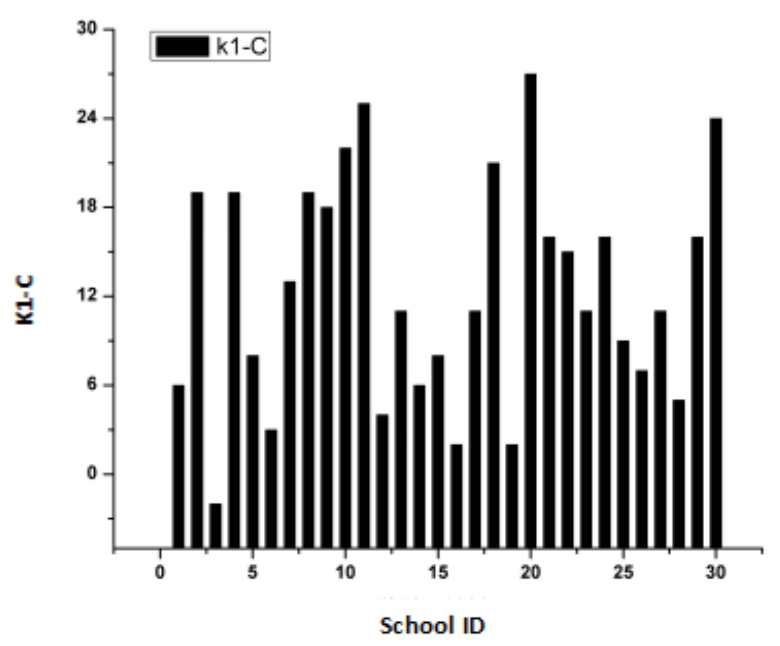

Fig.1 Relationship between $\mathrm{K}_{1}$ and $\mathrm{C}$

By using the DPS mathematical software, the data of the daily performance score $\mathrm{K}_{1}$ and the comprehensive score $\mathrm{C}$ expressed by quadratic polynomial, the results are as follow, $y=0.0176 x^{2}-2.2482 x+135.96, R^{2}=0.31$, which indicates that there is no significant correlation between $\mathrm{K}_{1}$ and $\mathrm{C}$.

It can be seen from Fig. 1 that the deviation of $\mathrm{K}_{2}-\mathrm{C}$ has a wide range of distribution, and most of the students deviation of $\mathrm{K}_{2}-\mathrm{C}$ is positive, which indicate that there is some difference between the final comprehensive score and the daily performance score. And the highest deviation is 27 . The 
authors analyze that the reason is generally that students interest in learning theoretical curriculum is not high, and their involvement is not high and these two paper-pen test scores are not high.

The theoretical curriculum teaching has always been one piece of "hard bone" in the higher vocational education, and compared with the practice curriculum of interactive participation, the theoretical curriculum teaching is relatively vague. Students usually feel bored and do not have the sense of participation, and the pure understanding ability is also the students' weakness in the higher vocational education. And the basic professional theoretical teaching is one indispensable part of the higher vocational education. Therefore, how to improve the teaching methods of the theoretical curriculum in higher vocational education is also one of the difficulty problems faced in front of the teachers in the higher vocational education.

In this reform and practice of teaching, a few students'deviation of $\mathrm{K}_{1}-\mathrm{C}$ is negative, which indicates that these students' daily performance score is slightly low, but their two paper-pen tests score are high. In the daily teaching process, in terms of learning interest of theoretical curriculum these students are significantly better than other students. They make speeches in the classroom more actively and have good habits of self - study after class.. What' s more their course work quality is comparatively excellent. The main reasons why their ordinary daily performance score is low are that their class attendance is relatively poor. In teaching process, the author finds that since these small part of students participate in various community activities the activities just conflict with the their courses. Therefore, the author believes that higher vocational colleges students' self-study after class is the main means to compensate for the limitations of the classroom teaching. Proper coordination of all kinds of social activities is the key to ensure the normal teaching order.

\subsection{2 $\mathrm{K}_{2}-\mathrm{C}$ deviation analysis}

The relationship of the deviation between the midterm test score $\mathrm{K}_{2}$ and the comprehensive score $\mathrm{C}$ is shown in Fig2.

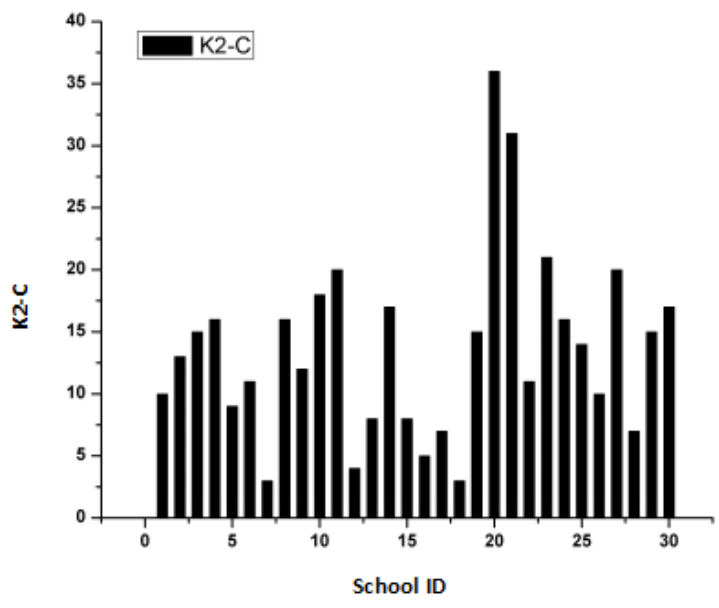

Fig.2 Relationship between $\mathrm{K}_{2}$ and $\mathrm{C}$

By using the DPS mathematical software, the data of the midterm test score $\mathrm{K}_{2}$ and the comprehensive score $\mathrm{C}$ are expressed by quadratic polynomial, and the results are as follow, $y=-0.0065 x^{2}+1.4115 x, R^{2}=0.0351$, which indicates that there is no significant correlation between $\mathrm{K}_{2}$ and $\mathrm{C}$.

It can be seen from Fig. 2 that the deviation of $\mathrm{K}_{2}-\mathrm{C}$ of the students in this class is all positive, which indicates that the midterm test score is generally better than the final comprehensive score. It can be also seen that as the students have a good grasp of the basic theoretical knowledge of the course, their midterm test scores $\mathrm{K}_{2}$ are all high. While the deviation of $\mathrm{K}_{2}-\mathrm{C}$ of very few students is more than 30, the authors realize that their final test scores $\mathrm{K}_{3}$ are too low resulting in their comprehensive correction coefficient $\mathrm{K}_{0}$ also very low. The purpose of setting mid-term test is to 
understand the learning status of the students, thus to make a teaching adjustment. And the following analysis reveals when the deviation of $\mathrm{K}_{2}-\mathrm{C}$ of most students is between 10 and 15 and that of a few students is under 5 , it is suitable that the ratio of $\mathrm{K}_{2}$ accounting for the final comprehensive score $\mathrm{C}$ is $30 \%$. This not only ensures most students' final scores objective, but also widens the score gap between students in high scores and low scores at a certain degree.

\section{$3.1 .3 \mathrm{~K}_{3}-\mathrm{C}$ deviation analysis}

The relationship of the deviation between the final test score $\mathrm{K}_{3}$ and the comprehensive score $\mathrm{C}$ is shown in Fig3.

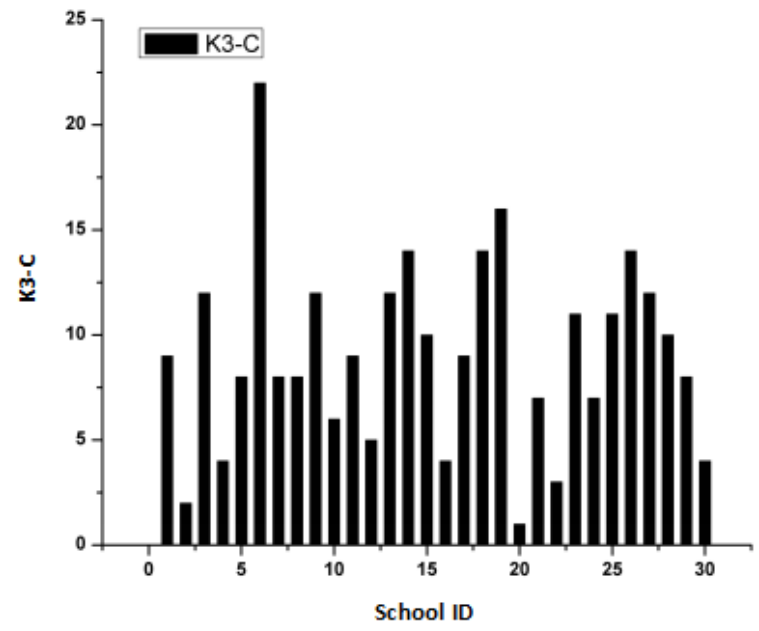

Fig.3 Relationship between $\mathrm{K}_{3}$ and $\mathrm{C}$

By using the DPS mathematical software, the data of the final test score $\mathrm{K}_{3}$ and the comprehensive score $\mathrm{C}$ is expressed by quadratic polynomial, and the results are as follow, $y=-0.0015 x^{2}+1.0214 x, R^{2}=0.80$,which indicates that there is an significant correlation between $\mathrm{K}_{3}$ and $\mathrm{C}$.

It can be seen from Fig. 3 that, the deviation of $\mathrm{K}_{3}-\mathrm{C}$ of the students in this class is all positive, which indicates that the final test scores are generally better than the final comprehensive scores. The deviation of $\mathrm{K}_{3}-\mathrm{C}$ of very few students is more than 15 , while that of most students is between 5 to 10 . Compared with Fig.2 it can be seen that, the deviation range of $\mathrm{K}_{3}-\mathrm{C}$ is obviously lower than that of $\mathrm{K}_{2}-\mathrm{C}$. This is because that after the midterm test, teachers improve their teaching methods, and students also have a new understanding of the theoretical curriculum of higher vocational education, and their ability to accept the teaching methods of theoretical knowledge has also been improved. The midterm pen-paper test plays a "touch stone" role in the half process. The authors reveal that the final test is a comprehensive test for the teaching effect of the course, and is different from the midterm test that is just a process try. And it is suitable that the ratio of $\mathrm{K}_{3}$ accounting for the final comprehensive score $\mathrm{C}$ is $40 \%$.

\subsection{4 $\mathrm{K}_{0}-\mathrm{C}$ deviation analysis}

The relationship of the deviation between the comprehensive correction coefficient $\mathrm{K}_{0}$ and the comprehensive score $\mathrm{C}$ is shown in Fig4. 


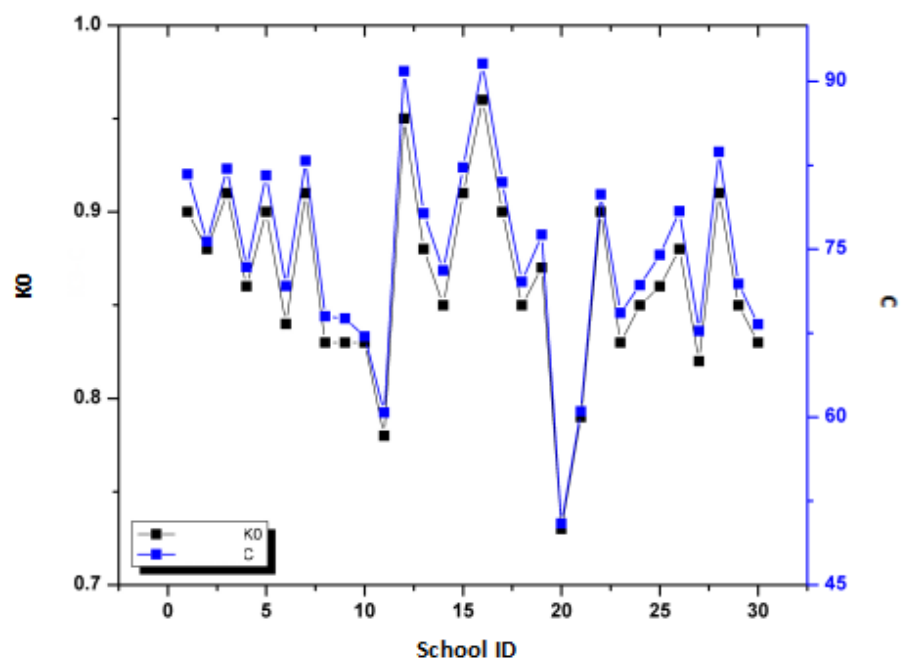

Fig.4 Relationship between $\mathrm{K}_{0}$ and $\mathrm{C}$

By using the DPS mathematical software, the data of the comprehensive correction coefficient $\mathrm{K}_{0}$ and the comprehensive score $\mathrm{C}$ is expressed by quadratic polynomial, and the results are as follow, $y=-8 E-05 x^{2}+0.0179 x, R^{2}=0.96$, which indicates that there is a high positive correlation between $\mathrm{K}_{0}$ and $\mathrm{C}$.

It can be seen from Fig. 4 that, the curve trend of $\mathrm{K}_{0}$ and that of $\mathrm{C}$ are almost the same. The original purpose of setting the comprehensive correction coefficient $\mathrm{K}_{0}$ is to secondarily regulate the final comprehensive score, and its main role is the magnifying glass for students 'comprehensive score gap, and increase the disparity of the students in high and low scores.

Through the data analysis of this reform and practice teaching, it can be seen that there is an obliviously positive correlation between $\mathrm{K}_{0}$ and $\mathrm{C}$, which reveals the importance of the daily performance score, the midterm score and the final score for the final comprehensive score, and highlights the significance of the whole process teaching mode. Secondly, by setting of the comprehensive correction coefficient $\mathrm{K}_{0}$, students are forced to pay attention to every aspect of the daily teaching process and to seek for the maximization of the comprehensive correction coefficient $\mathrm{K}_{0}$, avoiding to fall behind in the final comprehensive test process. This ensures the daily teaching order and the teaching effect in some extent. According to the authors observation of the daily teaching practice, students rarely have these phenomenon of absence, early going or late coming, and the quality of their homework is improved obviously compared with the previous teaching performance. Especially the activities of the interactive speech in classroom are improved, and the students learning attitude become better accordingly.

From Table 1 it can be seen that the deviation of the comprehensive correction coefficient $\mathrm{K}_{0}$ is up to 0.23 , which indicates that the differences between are large and highlights that $\mathrm{K}_{0}$ play an important role in screening the students in high and low scores.

\subsection{Analysis based on " $2+1+1 "$ comprehensive evaluation mode}

This reform and practice of the curriculum comprehensive evaluation system is carried out by using the " $2+1+1$ " whole teaching process identification model, which is based on the daily performance score $\mathrm{K}_{1}$, the midterm test score $\mathrm{K}_{2}$ and the final test score $\mathrm{K}_{3}$, and supplemented by the comprehensive correction coefficient $\mathrm{K}_{0}$. The results indicate that the final comprehensive scores are in line with the normal distribution, which are shown in Fig.5. 


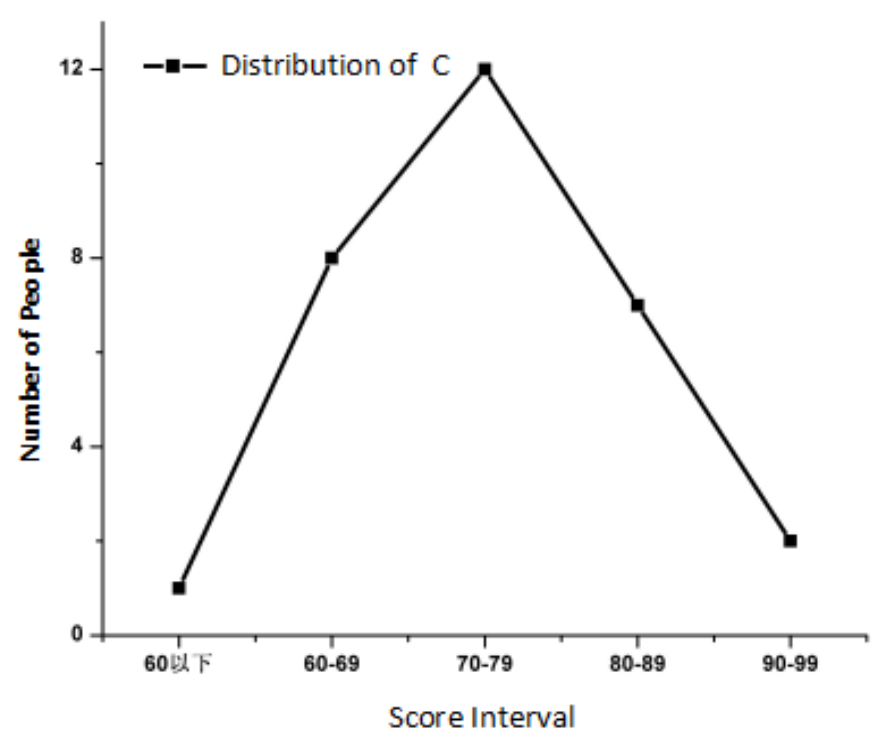

Fig.5 Distribution of final comprehensive score C

From Fig. 5 it can be seen that, the ratio of the final comprehensive score of more than 80 is $30 \%$, and the ratio of the final comprehensive score ranging from 70 to 79 is $40 \%$, while the failure ratio is less than $4 \%$. This result indicates that reform practice of the comprehensive ability identification mode " $2+1+1$ " has an significant effect on screening the students in high and low scores, and in the mean while reflects that the learning effects of most students are good.

This reform and practice of the curriculum comprehensive evaluation system has the following highlights. First of all, with the combination of midterm test and final test this mode increases students' store of knowledge involved in the tests, reduces the subjective tendency of the final test, and avoids limitations and injustice in the previous mode "final test giving the final word". This indicates that the combination of midterm test and final test mode is suitable for the evaluation of theoretical curriculum of the higher vocational education.

Secondly, the setting of the correction coefficient $\mathrm{K}_{0}$ forces students to pay attention to every aspect of the daily teaching process and to seek the maximization of $\mathrm{K}_{1}, \mathrm{~K}_{2}$ and $\mathrm{K}_{3}$ in exchange for the maximization of the comprehensive correction coefficient $\mathrm{K}_{0}$, thus to make an outstanding achievements of the final comprehensive score ultimately.

In the mean while, through the practice of " $2+1+1$ " mode of the whole process in teaching reform, the effectiveness of teaching is guaranteed.

By this reform and practice of teaching mode, it is proved that the identification factor ratio " $\mathrm{K}_{1} / \mathrm{K}_{2} / \mathrm{K}_{3}=30 \% / 30 \% / 40 \%$ " is an optimal option for the evaluation of theoretical core curriculum of the higher vocational education.

\section{Summary}

The following results were achieved through this teaching reform practice:

(a) The identification model of " $2+1+1$ ", which was based on the daily performance score $\mathrm{K}_{1}$, the midterm test score $\mathrm{K}_{2}$ and the final test score $\mathrm{K}_{3}$, and supplemented by the comprehensive correction coefficient $\mathrm{K}_{0}$, was suitable for the evaluation of theoretical core curriculum of the higher vocational education.

(b) The identification factor ratio " $\mathrm{K}_{1} / \mathrm{K}_{2} / \mathrm{K}_{3}=30 \% / 30 \% / 40 \%$ " was the optimal for the evaluation of theoretical core curriculum of the higher vocational education.

(c) This teaching reform practice has laid a theoretical and practical foundation for the construction of the comprehensive evaluation system of higher vocational education theoretical curriculum. 


\section{Acknowledgement}

This research was financially supported by the project "the integration and application of Internet technology and work-integrated learning in English teaching of vocational colleges" of higher education academy of Chongqing(Project No. CQGJ17188B) and the project "photocatalytic decomposition of organic wastewater by graphene complex" of the third batch of funding scheme for young backbone teachers in Chongqing colleges and universities.

\section{References}

[1] Miao Jinfeng, Wang Zheng, and Chang Yongqing,Problems and suggestions in the assessment of higher vocational courses ,Education and Vacation, Vol.21,pp. 186-187,2012.

[2] Ling Zhizhong and Ma Yunpeng, Curriculum evaluation model and Its Enlightenment to curriculum reform,Educational Research,vol.09.pp.31-36,1997.

[3] Xiu Pengyue and Yang Chun, Analysis of four factors influencing the evaluation of Higher Vocational Curriculum, China Higher Education,vol.20.pp.60-61,2006.

[4] Yang Qiliang, Out of the dilemma of curriculum evaluation reform, Educational Research, vol.09.pp.31-35,2005.

[5] Wang Zhongnan, Examination culture - the deep shackle of curriculum evaluation reform, Journal of East China Normal University(Educational Sciences), vol.01.pp.33-38,2013.

[6] Zhang Rui, Curriculum evaluation__ another practice platform for teachers' professional development, Education development research, vol.08.pp.74-77,2010.

[7] Li Nan, The characteristics of general education curriculum assessment in American universities and Its Enlightenment to China's Higher Vocational Ideological and political theory examination reform,Leading Journal of Ideological \& Theoretical Education,vol.05.pp.65-69, 2011.

[8] Mu Xiaoyong and Xue Jing, Curriculum evaluation—develop from academic achievement evaluation to academic evaluation,Educational theory and practice, vol.13.pp.46-49,2007.

[9] Luo Yingxia, The Reform of curriculum evaluation method and the improvement of the Higher Vocational Education quality, Vocational \& Technical Education Forum,vol.12.pp.50-52,2008. 